\title{
ANALISIS LAJU ALIRAN EJECTOR PADA SISTEM MED PLANT (Studi Kasus : PT PJB UBJ O \& M PLTU Indramayu)
}

\author{
Engkos Koswara \\ Teknik Mesin, Fakultas Teknik Universitas Majalengka \\ Email : ekoswara.ek@gmail.com
}

\begin{abstract}
ABSTRAK
MED plant merupakan sebuah bagian dari PLTU yang berfungsi untuk mengubah air laut menjadi air tawar. Air tawar tersebut digunakan sebagai fluida kerja di dalam sistem PLTU. Oleh karena itu, peran MED plant sangat penting dalam siklus PLTU. Tanpa adanya bahan baku siklus PLTU tidak akan berjalan.Tingkat keadaan air baku (air laut) sangat mempengaruhi persentase uap yang dihasilkan dari setiap efek. Uap ini yang akan terkondensasi menjadi air tawar pada efek berikutnya.Semakin banyak uap yang dihasilkan pada sistem MED plant semakin besar pula air tawar yang dihasilkan.Produksi uap yang dihasilkan sangat dipengaruhi oleh tekanan dari masing masing efek dan tekanan dari setiap efek sangat dipengaruhi oleh laju aliran pada sistem Ejector. Laju aliran pada sistem ejector pada sistem MED Plant sangat mempengaruhi tekanan pada masing - masing efek. Hasil perhitungan pada saat Commissioning : $V_{2-3}=1,485 \mathrm{~m} / \mathrm{s}, V_{2-9}=$ $17,046 \mathrm{~m} / \mathrm{s}, \quad V_{9-11}=16,437 \mathrm{~m} / \mathrm{s}, \quad V_{11-13}=15,22 \mathrm{~m} / \mathrm{s}, \quad V_{13-15}=13,393 \mathrm{~m} / \mathrm{s}$, $V_{15-17}=10,958 \mathrm{~m} / \mathrm{s}, V_{17-19}=7,914 \mathrm{~m} / \mathrm{s}, V_{19-21}=4,262 \mathrm{~m} / \mathrm{s}$. Pada kondisi saat ini : $V_{2-3}=17 \mathrm{~m} / \mathrm{s}, V_{2-9}=33,375 \mathrm{~m} / \mathrm{s}, \quad V_{9-11}=30,896 \mathrm{~m} / \mathrm{s}, \quad V_{11-13}=30,542 \mathrm{~m} / \mathrm{s}$, $V_{13-15}=28,146 \mathrm{~m} / \mathrm{s}, \quad V_{15-17}=24,53 \mathrm{~m} / \mathrm{s}, \quad V_{17-19}=18,815 \mathrm{~m} / \mathrm{s}, \quad V_{19-21}=$ $10,563 \mathrm{~m} / \mathrm{s}$.
\end{abstract}

\section{Kata kunci : MED plant, PLTU dan Uap.}

\section{Pendahuluan}

Dalam siklus PLTU membutuhkan air demineralisasi, hal ini dilakukan agar peralatan pada siklus PLTU tidak terjadi korosi. Sebelum memperoleh air demineralisasi terlebih dahulu diperlukan air tawar. Dikarenakan sulitnya memperoleh air tawar dalamjumlah besar, maka di dalam unit pembangkit tenaga uap peran desalinasi sangat diperlukan untuk penyediaan air tawar sebagai bahan baku produksi listrik.

Desalinasi adalah proses buatan untuk mengubah air asin (umumnya air laut) menjadi air tawar. PT PJB UBJ O \& M PLTU Indramayu memiliki MED Plant yang berfungsi sebagai pengubah air laut menjadi air tawar, dimana air tawar ini yang akan dijadikan sebagai air baku (raw water).

Dalam sistem MED plant, jumlah fraksi uap yang dihasilkan akan berpengaruh terhadap jumlah air tawar yang dihasilkan. Oleh karena itu, sangat penting untuk bisa mengetahui hal hal yang mempengaruhi produksi fraksi uap yang dihasilkan dari masing - masing Efek.

\section{Dasar Teori \\ 2.1Desalination plant}

Proses desalinasi dengan cara destilasi adalah pemisahan air tawar dengan cara merubah phase air, sedangkan pada proses dengan membran yakni pemisahan air tawar dari air laut dengan cara pemberian tekanan dan menggunakan membran reverse osmosis atau dengan cara elektrodialisa. Beberapa jenis teknologi proses desalinasi air laut dapat dilihat pada gambar 2.1.

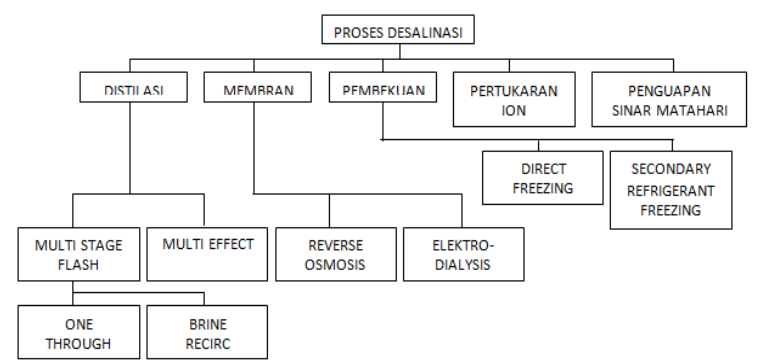

Gambar 2.1 Teknologi Proses Desalinasi

\subsection{Multi Efect Distilation}

Multi effect adalah suatu proses yang terdiri dari beberapa flash chamber yang disebut "effect". Dalam proses ini, hanya effect pertama yang dialiri uap dari boiler dan effect kedua dan 
selanjutnya memperoleh steam yang diproduksi oleh effect sebelumnya.

Dalam multi effect evaporator, air laut disemprotkan ke bagian luar dari tabung penukar panas yang diletakan secara horizontal. Pada saat uap air yang lebih panas yang terdapat dalam tabung berkondensasi dan menghasilkan air tawar, saat itu pula menyebabkan air laut diluar tabung mendidih, dan menghasilkan uap air baru yang kemudian mengalir ke tabung penukar panas berikutnya. Setiap effect mengurangi tekanannya dibawah tekanan jenuh dari temperatur brine (air laut yang pekat karena evaporasi).

\section{Metodologi}

\subsection{Tahapan - tahapan penelitian}

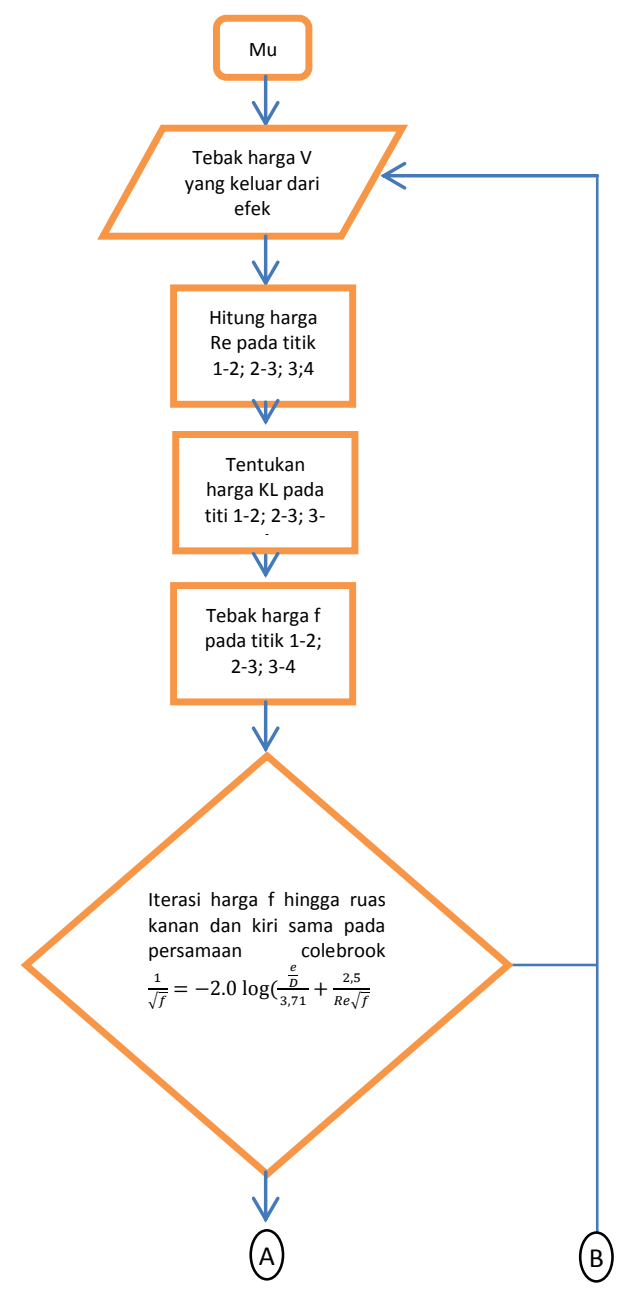

Proses kondensasi dan evaporasi berulang ulang sejak dari effect pertama hingga effect terakhir.

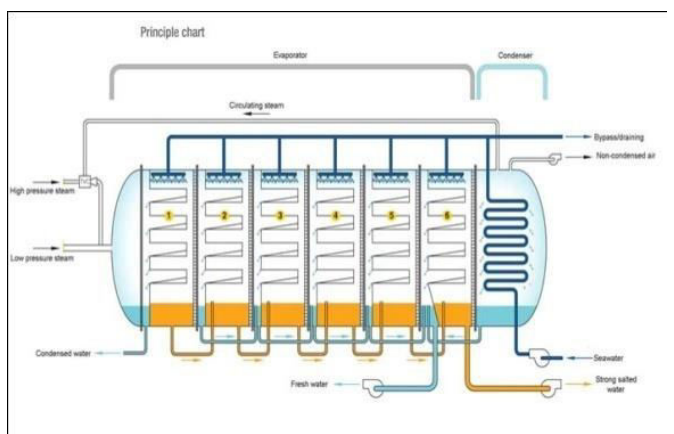

Gambar 2.2 Proses aliran multi effect distilation

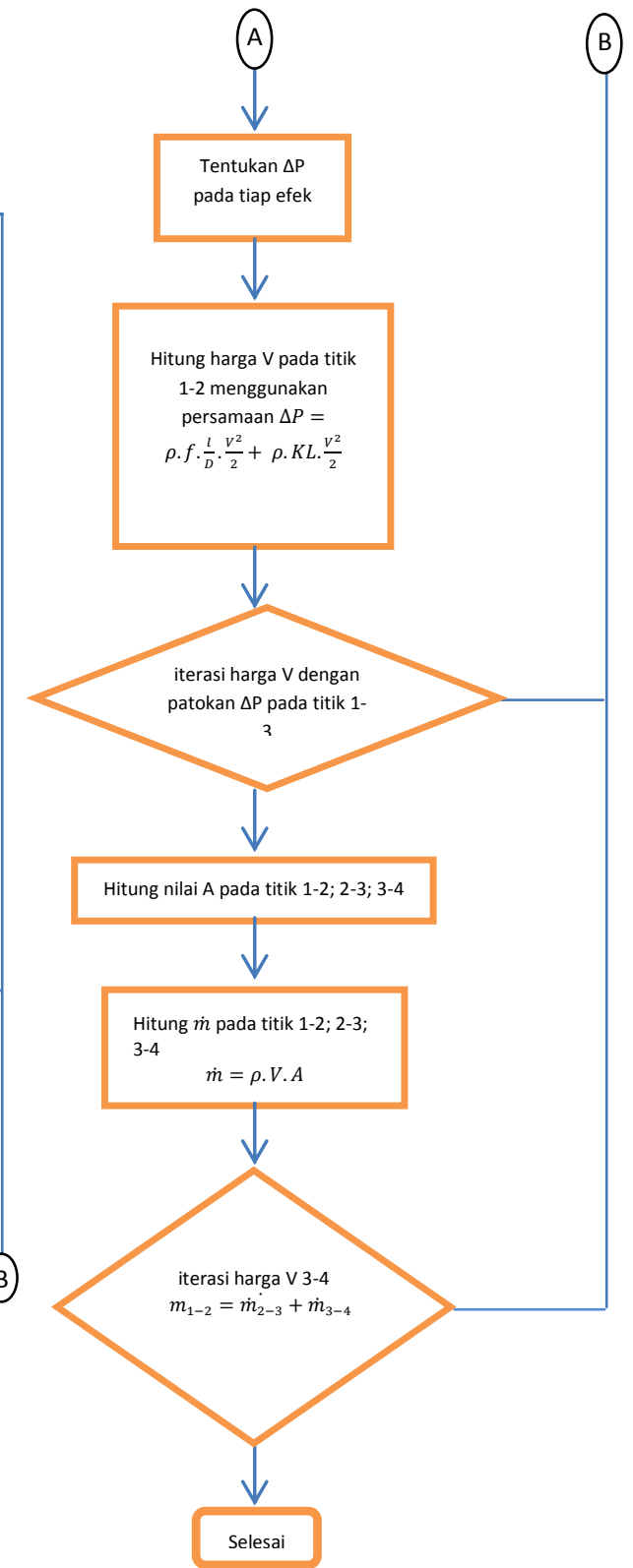




\section{Pembahasan}

\subsection{Produksi Air Tawar Kondisi Saat ini}

Dengan data fraksi uap yang dihasilkan dari tiap - tiap efek, maka produksi air tawar pada kondisi saat ini dapat dihitung menggunakan metode kesetimbangan. Berikut ini tabel produksi air tawar pada kondisi saat ini.

Tabel 4.1 Produksi Air Tawar Kondisi Saat ini

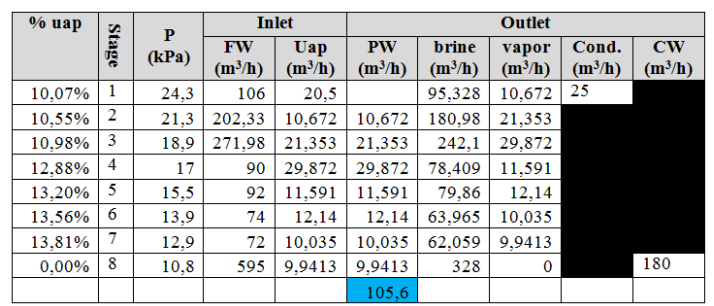

\subsection{Produksi Air Tawar Kondisi \\ Commissioning}

Dengan data fraksi uap yang dihasilkan dari tiap - tiap efek, maka produksi air tawar pada saat Commissioning dapat dihitung menggunakan metode kesetimbangan. Dengan mengacu pada data commissioning yang menghasilkan air tawar sebesar 151 ton/h.

Tabel 4.2 Produksi Air Tawar Kondisi Commissioning

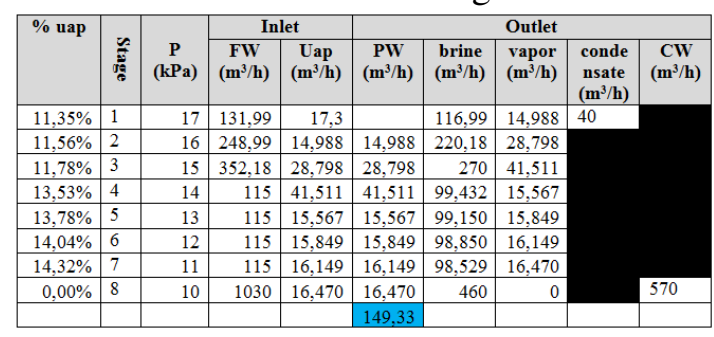

\subsection{Aliran pada Ejector}

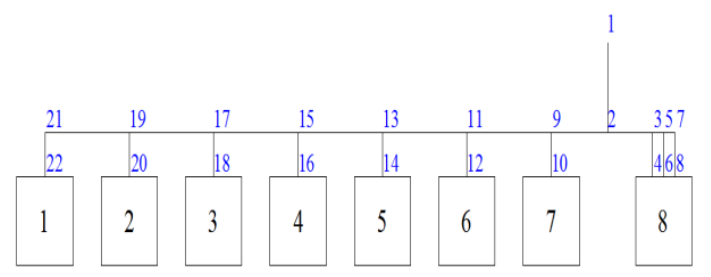

Gambar 4.1 Gambar sistem ejector pada MED Plant

\section{* Data kondisi bulan maret 2015}

Mengacu pada data kondisi bulan Maret 2015, dengan menggunakan algoritma di atas maka diperoleh laju aliran pada setiap pipa ejector sebagai berikut.
Tabel 4.3 kecepatan \& laju aliran maret 2015

\begin{tabular}{|c|c|c|c|c|c|}
\hline \multirow[b]{2}{*}{$\frac{y}{x}$} & \multicolumn{2}{|c|}{ Main Line } & \multicolumn{2}{|c|}{ Keluar Efek } & \multirow{2}{*}{$\begin{array}{c}\mathbf{P} \\
(\mathbf{k P a})\end{array}$} \\
\hline & $\begin{array}{l}\text { Flow } \\
\left(\mathrm{m}^{3} / \mathrm{s}\right)\end{array}$ & $\begin{array}{c}\mathbf{V} \\
(\mathrm{m} / \mathbf{s})\end{array}$ & $\begin{array}{l}\text { Flow } \\
\left(\mathrm{m}^{3} / \mathrm{s}\right)\end{array}$ & $\begin{array}{c}\mathbf{V} \\
(\mathrm{m} / \mathrm{s})\end{array}$ & \\
\hline 1 & 0,0868 & 10,5 & 0,0868 & 40,0 & 24,3 \\
\hline 2 & 0,1545 & 18,8 & 0,0678 & 31,3 & 21,3 \\
\hline 3 & 0,2015 & 24,5 & 0,047 & 21,6 & 18,9 \\
\hline 4 & 0,2312 & 28,1 & 0,0297 & 13,7 & 17 \\
\hline 5 & 0,2508 & 30,5 & $-0,019$ & $-9,09$ & 15,5 \\
\hline 6 & 0,2538 & 30,8 & $-0,003$ & $-1,34$ & 13,9 \\
\hline 7 & 0,2741 & 33,3 & 0,0204 & 9,40 & 12,9 \\
\hline 8 & 0,1396 & 17 & 0,0252 & 11,6 & 12,5 \\
\hline & 0,1145 & 13,9 & 0,0937 & 11,4 & 12,5 \\
\hline & 0,0207 & 2,52 & 0,0207 & 9,57 & 12,5 \\
\hline
\end{tabular}

\section{* Data Commissioning}

Pada keadaan commissioning, tekanan di tiap efek asumsikan terlebih dahulu. Dengan menggunakan algoritma di atas, dihitung kemungkinan terjadinya kondisi tekanan pada tiap efek tersebut.

Tabel 4.4 kecepatan \& laju aliran commissioning

\begin{tabular}{|c|c|c|c|c|c|}
\hline \multirow[b]{2}{*}{ 窇 } & \multicolumn{2}{|c|}{ Main Line } & \multicolumn{2}{|c|}{ Keluar Efek } & \multirow[b]{2}{*}{$\mathbf{P}(\mathbf{k P a})$} \\
\hline & $\begin{array}{l}\text { Flow } \\
\left(\mathbf{m}^{3} / \mathbf{s}\right)\end{array}$ & $\begin{array}{c}\mathbf{V} \\
(\mathbf{m} / \mathbf{s})\end{array}$ & $\begin{array}{l}\text { Flow } \\
\left(\mathrm{m}^{3} / \mathrm{s}\right)\end{array}$ & $\begin{array}{c}\mathbf{V} \\
(\mathbf{m} / \mathbf{s})\end{array}$ & \\
\hline 1 & 0,035 & 4,26 & 0,035 & 16,1 & 14,31 \\
\hline 2 & 0,065 & 7,91 & 0,03 & 13,8 & 13,93 \\
\hline 3 & 0,090 & 10,9 & 0,025 & 11,5 & 13,6 \\
\hline 4 & 0,11 & 13,3 & 0,02 & 9,23 & 13,24 \\
\hline 5 & 0,125 & 15,2 & 0,015 & 6,92 & 12,82 \\
\hline 6 & 0,135 & 16,4 & 0,01 & 4,61 & 12,37 \\
\hline 7 & 0,14 & 17,0 & 0,005 & 2,31 & 11,91 \\
\hline \multirow[t]{3}{*}{8} & 0,0122 & 1,48 & 0,002 & 0,92 & 11,64 \\
\hline & 0,0102 & 1,24 & 0,0055 & 0,67 & 11,64 \\
\hline & 0,0047 & 0,57 & 0,0047 & 0,57 & 11,64 \\
\hline
\end{tabular}

\subsection{Analisis laju aliran}

Produksi air tawar sangat dipengaruhi oleh tekanan pada tiap efek. Sedangkan tekanan pada tiap efek sendiri sangat dipengaruhi oleh laju aliran dari sistem ejector.

Tabel 4.5 Perbandingan Commissioning dan saat ini 


\begin{tabular}{|c|r|r|r|r|}
\hline \multirow{2}{*}{$\begin{array}{c}\text { Main } \\
\text { Line } \\
\text { Efek }\end{array}$} & \multicolumn{2}{|c|}{$\begin{array}{c}\text { Kecepatan Main } \\
\text { Line (m/s) }\end{array}$} & \multicolumn{2}{c|}{ Tekanan (Kpa) } \\
\cline { 2 - 5 } & Saat Ini & $\begin{array}{c}\text { Comm } \\
\text {. }\end{array}$ & $\begin{array}{c}\text { Saat } \\
\text { Ini }\end{array}$ & Comm. \\
\hline 1 & 10,563 & 4,262 & 24,3 & 14,31 \\
\hline 2 & 18,815 & 7,914 & 21,3 & 13,93 \\
\hline 3 & 24,533 & 10,958 & 18,9 & 13,6 \\
\hline 4 & 28,146 & 13,393 & 17 & 13,24 \\
\hline 5 & 30,542 & 15,22 & 15,5 & 12,82 \\
\hline 6 & 30,896 & 16,437 & 13,9 & 12,37 \\
\hline 7 & 33,375 & 17,046 & 12,9 & 11,91 \\
\hline 8 & 17 & 1,485 & 12,5 & 11,64 \\
\hline & 13,937 & 1,242 & 12,5 & 11,64 \\
\hline & 2,523 & 0,572 & 12,5 & 11,64 \\
\hline
\end{tabular}

Tabel 4.5 menunjukan perbandingan tekanan dan laju aliran pada kondisi saat bulan maret dan saat commissioning. Dari data tersebut, terlihat sangat signifikan perbedaan yang terjadi. Kecapatan untuk main line, pada kondisi bulan maret menunjukan $10,56 \mathrm{~m} / \mathrm{s}$ sedangkan saat commissioning menunjukan $4,262 \mathrm{~m} / \mathrm{s}$. Tekanan efek 1, pada kondisi bulan maret menujukan 24,3 $\mathrm{kPa}$ sedangkan pada saat commissioning 14,31 $\mathrm{kPa}$.

Pada kondisi bulan Maret, mampu menghasilkan air tawar sebesar 105 ton/h. Pada saat commissioning, mampu menghasilkan $152,31 \mathrm{~m}^{3} / \mathrm{h}$. Untuk mencapai angka produksi air tawar tersebut, tekanan pada tiap efek diubah sesuai dengan target produksi air tawar.

\section{Kesimpulan dan Saran \\ 5.1. Kesimpulan}

Kecepatan pada pipa utama untuk kondisi commissioning sampai efek 1 yaitu $4,262 \mathrm{~m} / \mathrm{s}$ sedangkan pada kondisi saat ini 10,563 m/s. Sedangkan tekanan efek 1 pada saat commissioning $14,31 \mathrm{kPa}$ sedangkan pada kondisi saat ini 24,3 kPa.

Laju aliran pada sistem ejector sangat mempengaruhi tekanan pada masing - masing Efek. Semakin cepat laju aliran, maka semakin tinggi tekanan pada setiap efek begitu juga sebaliknya. Hal inilah yang menjadi penyebab tidak langsung penurunan produksi air tawar.

\subsection{Saran}

Laju aliran pada sistem ejector sangat mempengaruhi tekanan pada masing - masing efek. Oleh karena itu, laju aliran sistem ejector perlu dijaga supaya tidak mengalami kenaikan. Ada beberapa hal yang mungkin dilakukan untuk menjaga laju aliran pada sistem ejector tidak mengalami kenaikan, diantaranya :

1. Menghilangkan kerak pada perpipaan di sistem ejector.
2. Meningkatkan tingkat kevakuman pada sistem ejector.

3. Menambahkan pompa vakum.

\section{DAFTAR PUSTAKA}

Artin Hatzikioseyian, Roza Vidali, Pavlina Kousi, "Modelling And Thermodynamic Analysis Of A Multi Effect Distillation (Med) Plant For Seawater Desalination", National Technical University of Athens (NTUA) GREECE.

Hisham El-Dessouky, "Steady-State Analysis of the Multiple Effect Evaporation Desalination Process",

Artin Hatzikioseyian, Roza Vidali, Pavlina Kousi, "Modelling And Thermodynamic Analysis Of A Multi Effect Distillation (Med) Plant For Seawater Desalination", National Technical University of Athens (NTUA) GREECE.

Hisham El-Dessouky, "Steady-State Analysis of the Multiple Effect Evaporation Desalination Process",

O. A. Hamed, "Thermal performance and exergy analysis of a thermal vapor compression desalination system", Department od chemical and petroleum engineering, faculty of Engineering, U.A.E. University. Philadelphia, 1995.

Hisham El-Dessouky,"analysis of single effect evaporator desalination system combined with vapor compression heat pump", chemical engineering department, kuwait university, 1997.

Logsheet sea water desalination PT PJB UBJ O $\&$ M PLTU INDRAMAYU. 